\title{
Protective Effect of Thymoquinone on Bisphenol A-Induced Hepatotoxicity in Male Rats, Targeting the Role of Associated Pro- Inflammatory Cytokines and NF-kB
}

Marwa H. Muhammed, Randa M. Mostafa, Mona A. said, Afnan I. Elgndy, Hend E. Elwakel

Department of physiology, Benha faculty of medicine, Banha University, Egypt.

Correspondence to: Afnan I. Elgndy Department of physiology, Benha faculty of medicine, Banha University, Egypt.

Email:

fonfonelgndy@gmail.com

Received: 29 October 2020

Accepted: 8 November 2020

\section{Abstract:}

Background: Bisphenol A (BPA) is one of the most abundant chemicals in the environment and prolonged exposure to BPA can cause oxidative stress and hepatotoxicity. Nigella sativa which containing Thymoquinone (TQ), have various therapeutic effects including hepatoprotective effect. Aim: The aim of this study was to evaluate the hepatotoxic effect of BPA on liver of adult male albino rats and the possible role of thymoquinone in alleviating the detrimental effects of BPA on the liver, targeting the role of associated pro-inflammatory cytokines and nuclear factor kappa B (NFkB). Method: The effect of BPA and TQ on albino rats was studied by estimating body weight changes (\%), liver index, serum alanine aminotransferase (ALT), aspartate aminotransferase (AST) \& gamma glutamyl transferase (GGT), tissue malondialdehyde (MDA), reduced glutathione (GSH), superoxide dismutase (SOD), tumor necrosis factor alpha (TNF- $\alpha)$, interleukin 1 beta (IL-1 $\beta$ ) and NFאB. Results: BPA caused significant increase in liver index, level of serum AST, ALT and GGT and hepatic tissue MDA, TNF- $\alpha$, IL-1 $\beta$ and NF- $\kappa B(P<0.05)$, while there is a significant decrease in hepatic tissue GSH \& SOD $(\mathrm{P}<0.05)$. Treatment with TQ+BPA cause significant increase in hepatic tissue GSH \& SOD $(\mathrm{P}<0.05)$, while there is a significant decrease in liver index, level of serum AST, ALT and GGT and hepatic tissue MDA, TNF- $\alpha$, IL-1 $\beta$ and $\mathrm{NF}-\kappa \mathrm{B}(\mathrm{P}<0.05)$. Conclusion: TQ protect against BPA-induced toxicity in male rats due to its antioxidant and anti-inflammatory actions so, TQ can be used as a therapeutic and preventive drug for hepatotoxicity resulting from toxicants, including BPA.

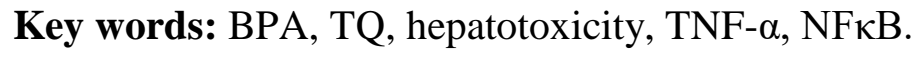



Abbreviations: ALT; alanine aminotransferase, AST; aspartate aminotransferase, BPA; bisphenol A, GGT; gamma glutamyl transferase, GSH; reduced glutathione, IL-1 $\beta$; interleukin 1 beta, MDA; malondialdehyde, NFאB; nuclear factor kappa B, SOD; superoxide dismutase, TNF- $\alpha$; tumor necrosis factor alpha, TQ; thymoquinone.

\section{Introduction:}

The liver plays an astonishing role in the homeostasis of the body. It is involved in almost all the biochemical pathways of growth, immunity, nutrient supply and energy provision. Thus, to maintain a healthy liver is a crucial factor for the overall health (1).

Toxic liver disease (hepatotoxicity) is responsible for $5 \%$ of all hospital admissions and $50 \%$ of all acute liver failures. Certain medicinal agents, when taken in overdoses and sometimes even when introduced within therapeutic ranges, may injure the liver. Other chemical agents, such as those used in laboratories and industries, natural chemicals and herbal remedies can also induce hepatotoxicity (2). Numerous pollutants harmfully affect development and physiology by interfering with normal functions of the body. They have become everywhere in the environment and are usually found in the tissues of humans and wildlife. One of these environmental contaminants is bisphenol A (BPA) (3).

BPA is used in the creation of polycarbonate plastic, such as plastic bottles, sports equipment, compact discs (CDs), digital versatile discs (DVDs), coatings on the inside of many food and beverage cans, polymers used in dental materials and also, on dermal contact with thermal papers widely used in cash register receipts. In 2015, an estimated 4 million tons of BPAderived chemical were produced, making it one of the highest volume of chemicals produced worldwide (4).

Our nature is surrounded by numerous plants that are used in the welfare of mankind including their use for dietary, medicinal, and curative purposes. Thymoquinone (TQ) is the most potent and abundant bioactive component of volatile oil of seeds of the medicinal plant; Nigella sativa (Black seeds). TQ has received enormous attention for its pharmacological properties and therapeutic potential. The major pharmacological activities exerted by TQ include anti-convulsant, anti-microbial, anti-cancer, anti-histaminic, anti-diabetic, anti-inflammatory, and anti-oxidant properties (5). 
This study was designed to demonstrate the hepatotoxic effect of BPA on liver of male albino rats and the possible role of thymoquinone in alleviating the detrimental effects of BPA on the liver, targeting the role of associated pro-inflammatory cytokines (TNF- $\alpha$ and IL-1 $\beta$ ) and NF- $\kappa B$.

\section{Material and methods:}

\section{Chemicals used:}

BPA was provided as white crystals from (Sigma-Aldrich Chemical Co., St. Louis, MO, USA. Lot NO: 201-245-8) and TQ was provided as faint orange crystalline powder from (Sigma-Aldrich Chemical Co., St. Louis, MO, USA. Lot NO: MKCB6982).

\section{Animals:}

This experimental study was achieved using 32 adult male albino rats aged above 2 months and the weight is between 180 and $220 \mathrm{~g}$. They were obtained from the animal research center, Faculty of Veterinary Medicine, Benha University. Each 4 rats were placed in a separate cage and were fed a standard diet, with free access to food and water. They were placed at room temperature $\left(25^{\circ} \mathrm{c}\right)$ with a $12: 12$-h light/dark cycle. These conditions were continued for 10 days before the experiment for acclimatization. The study period lasted for 5 weeks from July 2020 to august 2020 .
Experimental rats should be under complete healthy conditions all over the experiment and under care of a professional technician and a qualified researcher. All procedures were approved by ethical committee of Benha faculty of medicine. No rats were died throughout the experiment. At the end of the study the rats were incinerated at Benha university hospital incinerator.

\section{Experimental design:}

The rats included in this study were classified into 4 main groups; group I (control group) which are normal rats fed balanced animal diet and was received 0.3 $\mathrm{ml}$ ethanol (5\%), as TQ solvent, once daily and $0.3 \mathrm{~mL}$ olive oil, as BPA solvent, once daily for 5 weeks. Group II (BPA group) which was received BPA at a dose of 10 $\mathrm{mg} / \mathrm{kg} /$ day dissolved in $0.3 \mathrm{~mL}$ olive oil, by oral gavage, for 5 weeks, group III (TQ group) which was received TQ at a dose of $10 \mathrm{mg} / \mathrm{kg} /$ day dissolved in $0.3 \mathrm{ml}$ ethanol (5\%), by oral gavage, for 5 weeks and group IV (TQ+BPA group) which was received the same previous doses of TQ \& BPA.

\section{Procedure of the experiments:}

The initial and final body weights of each rat were recorded at the onset and at the end of the experiment for calculation of body weight change (\%). By the end of the study, after an overnight fasting, the animals were 
anesthetized with $\mathrm{Na}$ pentobarbital (40 $\mathrm{mg} / \mathrm{kg}$ ), then the animals were fixed on operating table. The abdominal cavities were opened and the blood samples were taken from abdominal aorta then were put into non-heparinized tubes and allowed to clot. Then the livers were excised, trimmed of excess fat, washed, and weighted.

Parameters assay:

- Body weight changes (\%) and liver index: The recorded initial and final body weights at the onset and the end of study were used for the calculation of body weight change (\%) as follow (6);

Body weight change $\%=$ Final body weight

- Initial body weight $\mathrm{x} 100$

\section{Final body weight}

Liver index is the relative weight of the liver

$\%$. It was determined as follow (7);

$$
\text { Liver Index }=\text { Liver weight }(g) \quad \text { x } 100
$$

\section{Final body weight (g)}

- Blood sampling and preparation of serum:

Serum was then separated from the clotted blood, by centrifugation at $5000 \mathrm{rpm}$ for 10 min, and stored at $-20^{\circ} \mathrm{C}$ till the assay of liver enzymes (ALT, AST and GGT) levels.

- Tissue sampling and preparation of liver homogenate:

Each liver was divided into three parts.
- The $1^{\text {st }}$ part was immediately washed with normal saline, kept in liquid nitrogen, and stored at $-20^{\circ} \mathrm{C}$ for the preparation of tissue homogenate, about $0.5 \mathrm{~g}$ of each liver was homogenized in $4.5 \mathrm{ml}$ of phosphate-buffered saline (PBS, $\mathrm{pH}$ 7.0, containing $1 \mathrm{~mm}$ EDTA). The crude tissue homogenate was then centrifuged at $8000 \mathrm{rpm}$ for $30 \mathrm{~min}$ and the supernatant was collected and stored at $4{ }^{\circ} \mathrm{C}$ till the assay of tissue MDA, GSH and SOD.

- The $2^{\text {nd }}$ part of the liver was homogenized in 5-10 $\mathrm{ml}$ cold buffer (50 $\mathrm{mM}$ potassium phosphate, $\mathrm{pH}$ 7.5) per gram tissue. The homogenates were centrifugated for 5 minutes at 5,000 x g. Then remove the supernatant and store at $\leq-20^{\circ} \mathrm{c}$ till the assay of tissue TNF- $\alpha$, IL$1 \beta$ and NFאB using ELISA.

- The 3rd part was kept in formaldehyde to be stained with Hematoxylin and Eosin for histopathological examination for signs of liver cell injury.

\section{Statistical analysis:}

The data were analyzed using the program: Statistical package for social science (SPSS) version 23.0 (SPSS Inc., Chicago, IL, USA, 2000). In the statistical comparison between the different groups, the significance of difference was tested using one-way analysis of variance (ANOVA) followed by Least 
Significant Difference (LSD) test for comparison between every two groups. The pvalues $<0.05$ were considered statistically significant.

Results:

Effect of BPA and TQ on body, liver weight and serum liver enzymes (ALT, AST \& GGT): (Table $1 \&$ fig. 1):

No statistically significant changes in body weight were recorded between different experimental groups when compared to the control group. While, liver index and serum level of ALT, AST, GGT was significantly increased in BPA-treated rats which is compared to the control group $(\mathrm{P}<0.05)$. In contrary, a significant decrease was observed in these parameters in rats administered TQ together with BPA $(\mathrm{P}<0.05)$, compared to BPA-treated rats although the value did not reach the normal value of the control group. Daily administration of TQ alone induced nonsignificant change as compared to the control group.

Effect of BPA and TQ on the level of hepatic tissue MDA, GSH, SOD, TNF- $\alpha$,

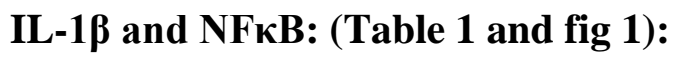

BPA cause significant increase in the hepatic tissue level of MDA, TNF- $\alpha$, IL- $1 \beta$ and NF-kB $(\mathrm{P}<0.05)$. Our results also revealed non-significant changes in these biomarkers in rats treated with TQ alone for 5 weeks as compared to the control. Administration of TQ together with BPA significantly improved their level although it could not bring values of these indices to that of the control group $(\mathrm{P}<0.05)$

While administration of BPA induced a significant decrease in GSH and SOD $(\mathrm{P}<0.05)$. Supplementation with TQ for 5 weeks significantly improved the suppressed antioxidants in the BPA-treated rats $(\mathrm{P}<0.05)$. But administration of TQ alone has a non-significant effect on the antioxidative status of the liver compared to the control group.

Effect of BPA and TQ on histopathological changes of the liver: (Table 1):

In control group (group I), liver sections showed a normal histological structure of hepatic tissue that showed a thread like arrangement of hepatocyte cells (figure 3-I). While, in (figure 3-II), liver specimen of rats received BPA alone (group II) shows disruption of hepatocytes, necrotic changes of hepatocytes which were particularly pronounced in the centrilobular area, inflammatory cell infiltration, vascular congestion and sinusoidal dilatation. Liver specimen of rats received TQ alone (group 
III) revealed that liver morphology was similar to the control group (figure 3-III). Finally, (figure 3-IV) represents liver specimen of rats received TQ+BPA (group IV) and showed that TQ markedly reduced the hepatocellular changes, as compared with those in the BPA group such as decreased necrosis, decreased inflammatory cell infiltration, decreased vascular congestion and decreased disruption of hepatocytes in liver tissue.

Table 1: Comparison of body weight changes (\%), liver index, serum ALT, AST \& GGT, tissue MDA, GSH \& SOD, tissue TNF- $\alpha$, IL-1 $\beta$ \& NFkB between control, BPA, TQ and BPA+TQ groups

\begin{tabular}{|c|c|c|c|c|c|}
\hline Groups & Control group (I) & BPA group (II) & TQ group (III) & TQ+ BPA group (IV) & P value \\
\hline Body weight changes (\%) & $19.41 \pm 1.51$ & $19.65 \pm 0.80$ & $18.29 \pm 1.12$ & $19.47 \pm 1.14$ & $>0.05$ \\
\hline Liver index (\%) & $4.24 \pm 0.21^{\mathrm{b}, \mathrm{d}}$ & $5.69 \pm 0.25^{\mathrm{a}, \mathrm{c}, \mathrm{d}}$ & $4.25 \pm 0.20^{\mathrm{b}, \mathrm{d}}$ & $4.77 \pm 0.09^{\mathrm{a}, \mathrm{b}, \mathrm{c}}$ & $<0.05$ \\
\hline $\operatorname{ALT}(\mathbf{U} / \mathbf{L})$ & $50.74 \pm 6.45^{\mathrm{b}, \mathrm{d}}$ & $79.55 \pm 7.51^{\mathrm{a}, \mathrm{c}, \mathrm{d}}$ & $51.69 \pm 5.57^{\mathrm{b}, \mathrm{d}}$ & $64.98 \pm 4.15^{\mathrm{a}, \mathrm{b}, \mathrm{c}}$ & $<0.05$ \\
\hline $\operatorname{AST}(\mathbf{U} / \mathbf{L})$ & $45.3 \pm 5.80^{\mathrm{b}, \mathrm{d}}$ & $90.44 \pm 10.46^{\mathrm{a}, \mathrm{c}, \mathrm{d}}$ & $47.01 \pm 4.14^{\mathrm{b}, \mathrm{d}}$ & $71.21 \pm 6.97^{\mathrm{a}, \mathrm{b}, \mathrm{c}}$ & $<0.05$ \\
\hline GGT (U/L) & $2.63 \pm 0.10^{\mathrm{b}, \mathrm{d}}$ & $5.55 \pm 0.20^{\mathrm{a}, \mathrm{c}, \mathrm{d}}$ & $2.72 \pm 0.10^{\mathrm{b}, \mathrm{d}}$ & $3.92 \pm 0.10^{\mathrm{a}, \mathrm{b}, \mathrm{c}}$ & $<0.05$ \\
\hline MDA (nmol/gm tissue) & $1.11 \pm 0.08^{\mathrm{b}, \mathrm{d}}$ & $3.40 \pm 0.15^{\mathrm{a}, \mathrm{c}, \mathrm{d}}$ & $1.03 \pm 0.06^{\mathrm{b}, \mathrm{d}}$ & $1.40 \pm 0.08^{\mathrm{a}, \mathrm{b}, \mathrm{c}}$ & $<0.05$ \\
\hline GSH (mg/gm tissue) & $39.47 \pm 2.12^{\mathrm{b}, \mathrm{d}}$ & $18.87 \pm 1.95^{\mathrm{a}, \mathrm{c}, \mathrm{d}}$ & $40.39 \pm 2.38^{\mathrm{b}, \mathrm{d}}$ & $32.56 \pm 1.10^{\mathrm{a}, \mathrm{b}, \mathrm{c}}$ & $<0.05$ \\
\hline SOD (U/gm tissue) & $71.08 \pm 2.97^{\mathrm{b}, \mathrm{d}}$ & $41.67 \pm 2.1^{\mathrm{a}, \mathrm{c}, \mathrm{d}}$ & $73.14 \pm 1.85^{\mathrm{b}, \mathrm{d}}$ & $62.86 \pm 3.57^{\mathrm{a}, \mathrm{b}, \mathrm{c}}$ & $<0.05$ \\
\hline TNF- $\alpha$ (pg/gm tissue) & $35.5 \pm 4.87^{\mathrm{b}, \mathrm{d}}$ & $80.38 \pm 4.27^{\mathrm{a}, \mathrm{c}, \mathrm{d}}$ & $34.38 \pm 6.48^{\mathrm{b}, \mathrm{d}}$ & $52.75 \pm 3.65^{\mathrm{a}, \mathrm{b}, \mathrm{c}}$ & $<0.05$ \\
\hline IL-1ß (pg/gm tissue) & $86.38 \pm 3.66^{\mathrm{b}, \mathrm{d}}$ & $181.25 \pm 6.63^{\mathrm{a}, \mathrm{c}, \mathrm{d}}$ & $83.88 \pm 4.88^{\mathrm{b}, \mathrm{d}}$ & $101.63 \pm 4.78^{\mathrm{a}, \mathrm{b}, \mathrm{c}}$ & $<0.05$ \\
\hline NFкB (pg/gm tissue) & $1.36 \pm 0.04^{\mathrm{b}, \mathrm{d}}$ & $4.36 \pm 0.10^{\mathrm{a}, \mathrm{c}, \mathrm{d}}$ & $1.44 \pm 0.06^{\mathrm{b}, \mathrm{d}}$ & $2.06 \pm 0.12^{\mathrm{a}, \mathrm{b}, \mathrm{c}}$ & $<0.05$ \\
\hline $\begin{array}{l}\text { Histopathological injury } \\
\text { score }\end{array}$ & $0.0 \pm-^{b, d}$ & $5.25 \pm 0.89^{\mathrm{a}, \mathrm{c}, \mathrm{d}}$ & $0.0 \pm-^{\mathrm{b}, \mathrm{d}}$ & $1.88 \pm 0.83^{\mathrm{a}, \mathrm{b}, \mathrm{c}}$ & $<0.05$ \\
\hline
\end{tabular}

Data are represented as Mean $\pm \mathrm{SD}$ :

${ }^{a}$ sig from Group I - ${ }^{b}$ sig from Group II - ${ }^{c}$ sig from Group III - ${ }^{d}$ sig from Group IV

- P value $<0.05$ was considered statistically significant

- $\mathrm{P}$ value $>0.05$ was considered statistically insignificant

ALT: Alanine aminotransferase; AST: Aspartate aminotransferase; GGT: Gamma glutamyl transferase; MDA: Malondialdehyde; GSH: Reduced glutathione; SOD: Superoxide dismutase; TNF- $\alpha$ : Tumor necrosis factor alpha; IL-1ß: Interleukin-1 beta; NFкB: Nuclear factor kappa B 


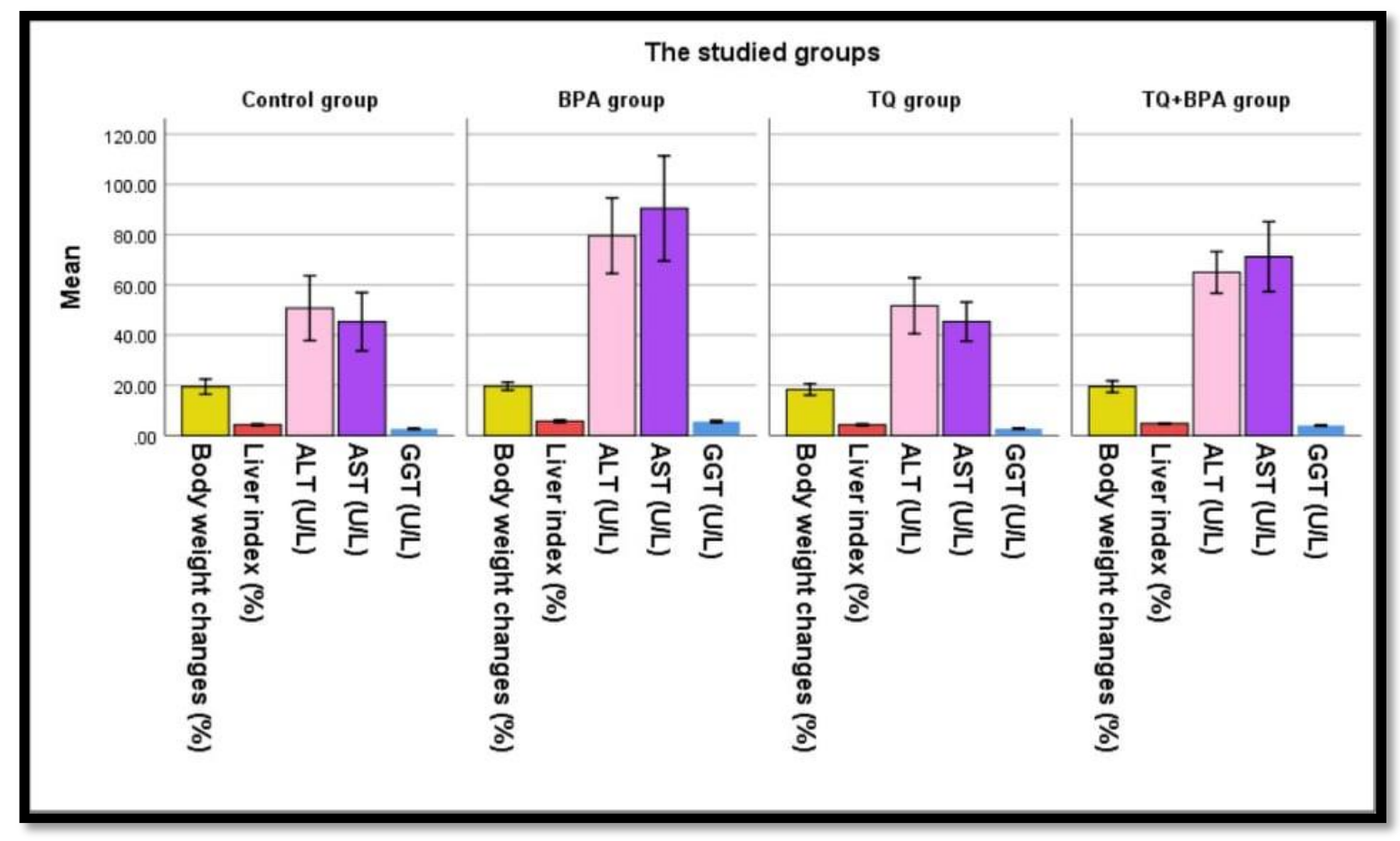

Figure (1): Mean body weight changes (\%), liver index (\%), serum ALT, AST \& GGT levels in studied groups

BPA: Bisphenol A; TQ: Thymoquinone; ALT: Alanine aminotransferase; AST: Aspartate aminotransferase; GGT: Gamma glutamyl transferase

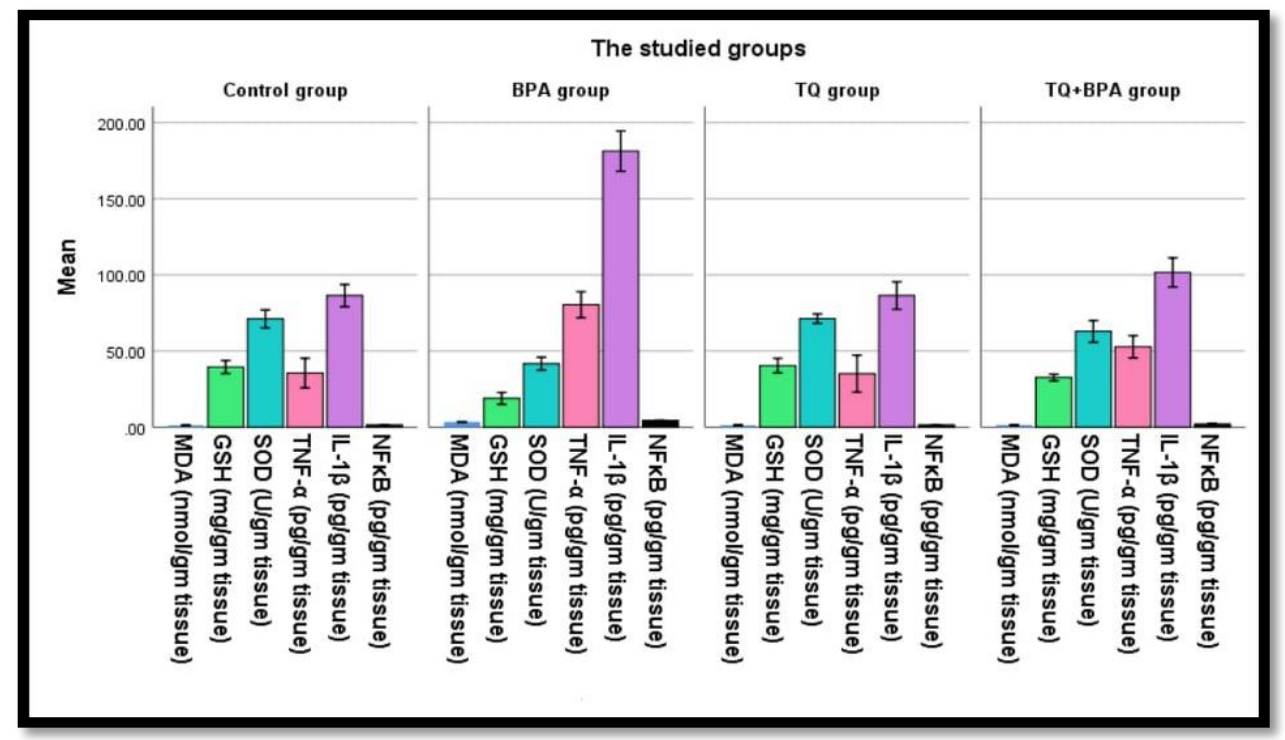

Figure (2): Mean tissue MDA, GSH, SOD, TNF- $\alpha$, IL-1 $\beta$ \& NFאB levels in studied groups

BPA: Bisphenol A; TQ: Thymoquinone; MDA: Malondialdehyde; GSH: Reduced glutathione; SOD:

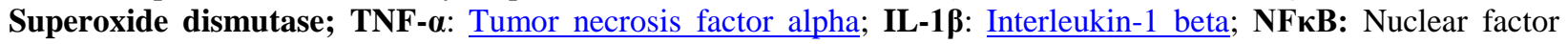
kappa B 


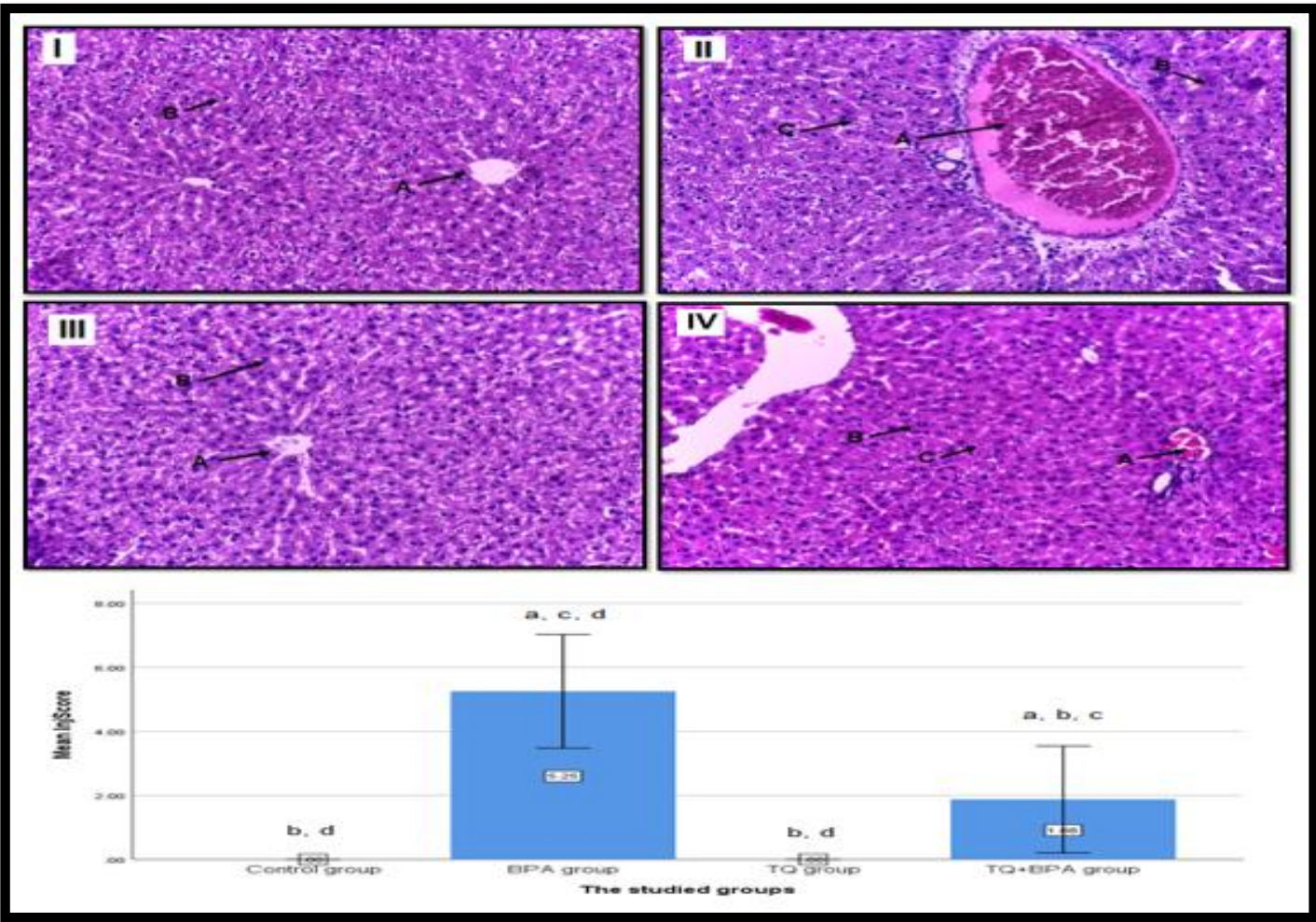

Figure (3): Mean histopathological score \& histopathological changes of the liver in studied groups

(I): Control group: showing histological structure of hepatic lobule: (A): Central vein, (B): Normal hepatocytes; (II): BPA group: showing vascular congestion (A), inflammatory cell infiltration (B) \& necrotic changes of hepatocytes (C); (III): TQ group showing normal histological structure of hepatic lobule: (A): Central vein, (B): Normal hepatocytes \& (IV): BPA+TQ group: showing mild vascular congestion (A), reduced inflammatory cell infiltration (B) \& reduced necrotic changes of hepatocytes (C), (H \& E X 200).

\section{Discussion:}

The liver is involved in the major biochemical and signaling pathways associated with homeostasis and plays a crucial role in interacting with and fighting against xenobiotics. Among these, BPA; which is a fairly prevalent compound with certain risks to human health and various body systems including the liver (8).The black seed (Nigella sativa), a nutritional flavoring agent, is known to have healing potentials and has been used as folk medicine in middle and far east for a wide range of diseases. TQ, is one of the active ingredients of Nigella sativa seeds which has many pharmacological effects (9). Our study showed the protective effect of TQ against the BPA -induced hepatotoxicity.

In the current study, daily administration of BPA for 5 weeks resulted in hepatic injury 
and toxicity indicated by significant elevation in liver index and the activity of liver enzymes (ALT, AST, and GGT) in the serum in comparison with the control group. These results are confirmed by the histopathological examination of the liver. While, body weight in BPA-treated rats did not show significant changes in comparison with the control group (table 1 and fig. 1). The present findings are in agreement with the previous studies $(\mathbf{1 0}, \mathbf{1 1}, \mathbf{1 2}, \mathbf{1 3})$. Since liver is the primary site for getting rid of xenobiotics, the observed increase in its weight may represent a homeostatic mechanism to deliver more BPA into the liver for detoxification. (14). Also, it may be due to inflammatory cell infiltration caused by hepatotoxicity (8). Liver function tests are routinely used as diagnostic markers for hepatotoxicity. ALT, AST and GGT are the major markers in monitoring the functional status of liver. The ALT activity is an important index to measure the degree of cell membrane damage while AST is an indicator of mitochondrial damage. The activity of GGT is a marker of hepatic injury. Increased levels of hepatic marker enzymes indicate the permeability and/or necrosis of hepatocytes causing excess cellular leakage and loss of membrane integrity of hepatocytes which caused by BPA (10).
Treatment with TQ significantly suppressed the BPA-induced elevation in liver index and the activity of ALT, AST and GGT in serum in TQ+BPA treated rats in comparison with BPA-treated group. These results are confirmed by the histopathological examination of the liver (table 1 and fig. 1). These results come in concert with previous studies $(\mathbf{1 5}, \mathbf{1 6}, \mathbf{1 7}$, 18). The observed decrease in liver index in TQ+BPA treated rats may be due to protective effect of thymoquinone against liver inflammation and enlargement caused by BPA (10). The efficacy of TQ in protecting hepatic enzyme leakage may be related to its ability to preserve the structural and functional integrity of the liver against the adverse effects of BPA as well as repair of hepatic tissue damage caused by BPA. TQ was found to reduce hepatic dysfunction through its membrane stabilization properties against ROS-mediated hepatocellular injury (19). Treatment with TQ prevented some of the histopathological changes of BPA such as necrosis and decreased disruption of hepatocytes in liver tissue due to its strong antioxidative activity and anti-inflammatory effect (15).

In our study, we assessed oxidative stress markers, inflammatory markers and NF- $\mathrm{NB}$; as the level of tissue MDA, TNF- $\alpha$, IL-1 $\beta$ and NF-кB were significantly increased 
While, GSH and SOD content were significantly reduced in hepatic tissue in BPA-treated group in comparison with the control group (table 1 and fig. 2). BPA has been proposed to induce hepatic damage and mitochondrial dysfunction through induction of oxidative stress (20). BPA not only initiates lipid peroxidation but also reduces the tissue antioxidants GSH and SOD activities which is consistent with previous studies (8, 11, 12). The hepatic inflammatory response is mediated by proinflammatory cytokines, especially TNF$\alpha$, the release of which is one of the first events in many types of liver injury, such as induced by BPA and further modulates the effects of other cytokines, such as IL-1 $\beta$ (21). ROS and free radicals induce the upregulation of proinflammatory cytokines TNF- $\alpha$ and IL-1 $\beta$ in necrotic hepatocytes (22). Increased proinflammatory cytokines and ROS triggers those kinase pathways that results in NF- $\kappa \mathrm{B}$ activation. As a result of its activation, NF- $\kappa \mathrm{B}$ transfers to the nucleus of the hepatic cell, binds to DNA and upregulates the transcription of many inflammatory genes like cytokine (such as TNF- $\alpha$, IL-1 $\beta, \quad$ IL-6, and IL-8) and chemokine causing the inflammatory changes that occur in BPA- induced hepatotoxicity (23). This result come in concert with previous studies $(\mathbf{2 4}, \mathbf{2 5})$.
TQ significantly reduced the BPA-induced oxidative stress as indicated by the significant reduction in lipid peroxidation and MDA production, TNF- $\alpha$, IL-1 $\beta$ and NF- $\kappa \mathrm{B}$ and a significant increase in GSH \& SOD in hepatic tissue in TQ+BPA treated rats in comparison with BPA-treated group (table 1 and fig. 2). These results supporting the protective effect of TQ as antioxidant and anti-inflammatory agent. Our result was in agreement with other studies $(\mathbf{1 6}, \mathbf{1 7}, \mathbf{1 8})$. The protective effect of TQ against lipid peroxidation produced by BPA can be attributed to its strong scavenging properties and its ability to reduce free radicals production. (9). While, the observed restoration of GSH and SOD activities in our study on pretreatment with TQ may be due to direct stimulatory effect of TQ on GSH and SOD (17). TQ also, cause suppression of inflammatory stimuliinduced activation of NF-kB. So, TQ can reduce inflammation by its antioxidant properties and its inhibitory effect on the release of the inflammatory mediators; TNF$\alpha$ and IL-1 $\beta$ and consequently inhibiting the $\mathrm{NF}-\kappa \mathrm{B}$ pathways (16).

\section{Conclusion:}

From the current study, it may be concluded that BPA has a detrimental effect on liver of male rats and TQ plays a notable role in 
protecting the liver against BPA-induced toxicity in male rats. The strong antioxidative activity and anti-inflammatory action could partially be the mechanism underlying the protective effects of thymoquinone. So, TQ can be used as a natural therapeutic and preventive drug for hepatotoxicity resulting from toxicants, including BPA.

\section{References:}

1. Pandit A, Sachdeva T \& Bafna P (2012): DrugInduced Hepatotoxicity: A Review. Journal of Applied Pharmaceutical Science; 02 (05): 233 243.

2. Ostapowicz G, Fontana RJ, Schiødt FV, Larson A, Davern TJ, Han SH, et al. (2002): Results of a prospective study of acute liver failure at 17 tertiary care centers in the United States. Ann Intern Med; 137 (12): 947-54.

3. Stacy SL, Papandonatos GD, Calafat AM, Chen A, Yolton K, Lanphear BP, et al. (2017): Early life bisphenol $\mathrm{A}$ exposure and neurobehavior at 8 years of age: identifying windows of heightened vulnerability. Environment international; 107: 258-265.

4. Pivnenko K, Pedersen GA, Eriksson E \& Astrup TF (2015): Bisphenol A and its structural analogues in household waste paper. Waste Management; 44: 39-47.

5. Darakhshan S, Pour AB, Colagar AH \& Sisakhtnezhad S (2015): Thymoquinone and its therapeutic potentials. Pharmacol Res; 95: 138158.

6. Lee S, Nam H, Kim J, Cho H, Jang Y, Lee E, et al. (2012): Body weight changes of laboratory animals during transportation. Asian-Australasian journal of animal sciences; 25(2): 286.

7. Kim J, Kim CJ, Ko IG, Joo SH \& Ahn HJ (2012): Splenectomy affects the balance between hepatic growth factor and transforming growth factor- $\beta$ and its effect on liver regeneration is dependent on the amount of liver resection in rats. Journal of the Korean Surgical Society; 82(4): 238-245.

8. Zaulet M, Kevorkian SEM, Dinescu S, Cotoraci C, Suciu M, Herman H, et al. (2017): Protective effects of silymarin against bisphenol A-induced hepatotoxicity in mouse liver. Experimental and therapeutic medicine; 13(3): 821-828.

9. Nagi MN, Alam K, Badary OA, Al-Shabanah OA, Al-Sawaf HA \& Al-Bekairi AM (1999): Thymoquinone protects against carbon tetrachloride hepatotoxicity in mice via an antioxidant mechanism. Biochem Mol Biol Int; 47 (1): 153-159.

10. Abdel-Wahab WM (2014): Thymoquinone Attenuates Toxicity and Oxidative Stress Induced by Bisphenol A in Liver of Male Rats. Pakistan Journal of Biological Sciences; 17 (11): 11521160.

11. Korkmaz A, Ahbab MA, Kolankaya D \& Barlas N (2010): Influence of vitamin C on bisphenol A, nonylphenol and octylphenol induced oxidative damages in liver of male rats. Food and Chemical Toxicology; 48 (10): 2865-2871.

12. Hassan ZK, Elobeid MA, Virk P, Omer SA, ElAmin M, Daghestani MH, et al. (2012): Bisphenol A induces hepatotoxicity through oxidative stress in rat model. Oxid Med Cell Longev. (2012): 194829.

13. Elhamalawy OH, Eissa FI, El Makawy AI \& ELBamby MM (2018): Bisphenol-A Hepatotoxicity and the Protective Role of Sesame Oil in Male 
Mice. Jordan Journal of Biological Sciences; 11 (4): 461-467.

14. Schulte-Hermann R (1979): Adaptive liver growth induced by xenobiotic compounds: Its nature and mechanism. Arch Toxicol 2: 113-124.

15. Ahmadabadi A, Alibolandi $\mathrm{P}$, Ranjbar A, Mousavi L, Nili-Ahmadabadi H, LarkiHarchegani A, et al. (2018): Thymoquinone attenuates hepatotoxicity and oxidative damage caused by diazinon: an in vivo study. Research in pharmaceutical sciences; 13 (6): 500-508.

16. Al-malki AL \& Sayed AAR (2014): Thymoquinone attenuates cisplatin-induced hepatotoxicity via nuclear factor kappa- $\beta$. BMC Complementary and Alternative Medicine;14 (1): $1-8$.

17. Alsaif MA (2007): Effect of Thymoquinone on Ethanol-Induced Hepatotoxicity in Wistar Rats. Journal of Medical Sciences; 7 (7): 1164-1170.

18. Suddek GM (2014): Protective role of thymoquinone against liver damage induced by tamoxifen in female rats. Can $\mathbf{J}$ Physiol Pharmacol; 92 (8): 640-644.

19. Basiglio CL, Pozzi EJS, Mottino AD \& Roma MG (2009): Differential effects of silymarin and its active component silibinin on plasma membrane stability and hepatocellular lysis. Chem Biol Interact; 179 (2-3): 297-303.

20. Moon MK, Kim MJ, Jung IK, Koo YD, Ann HY, Lee KJ, et al. (2012): Bisphenol A impairs mitochondrial function in the liver at doses below the no observed adverse effect level. Journal of Korean Medical Science; 27 (6): 644-652.

21. Weiss MJ (2012): Cytokines in liver, biliary and pancreatic disease. In: Jarnagin $\mathrm{W}$ editor. Blumgart's Surgery of the Liver, Pancreas and Biliary Tract. 5th Elsevier, Inc; 166-180.

22. Ali HM, Al-Rasheed NoM, Fadda LM, AlRasheed NaM \& Yacoub HI (2016): DownRegulation of NFkB, Bax, TGF- $\beta$, Smad-2mRNA expression in the Livers of Carbon Tetrachloride Treated Rats using Different Natural Antioxidants. Braz Arch Biol Technol; v.59: e16150553.

23. Igor OM, Fabiane F, Camila $R C$ \& Giuseppina L (2016): Antioxidant Activity of $\gamma$-Oryzanol: A Complex Network of Interactions. Inter $\mathrm{J}$ of $\mathrm{Mol}$ Sc; 17 (8): 1107.

24. Zhu J, Jiang L, Liu Y, Qian W, Liu J, Zhou J, et al. (2015): $\mathrm{MAPK}$ and $\mathrm{NF}-\kappa \mathrm{B}$ pathways are involved in bisphenol A-induced TNF- $\alpha$ and IL-6 production in BV2 microglial cells. Inflammation; 38(2): 637-648.

25. Li Y, Burns KA, Arao Y, Luh CJ \& Korach KS (2012): Differential estrogenic actions of endocrine-disrupting chemicals bisphenol A, bisphenol AF, and zearalenone through estrogen receptor alpha and beta in vitro. Environmental Health Perspectives; 120 (7): 1029-1035.

To cite this article: Marwa H. Muhammed, Randa M. Mostafa, Mona A. said, Afnan I. Elgndy, Hend E. Elwakel. Protective Effect of Thymoquinone on Bisphenol A-Induced Hepatotoxicity in Male Rats, Targeting the Role of Associated Pro-Inflammatory Cytokines and NF-kB. BMFJ 2021;38 (academic issue): 61-72. DOI: 10.21608/bmfj.2020.48098.1335 